\title{
ALGORITHMS OF THE OPERATION OF A SELF-CONTAINED SYSTEM FOR SLOWING DOWN THE ROTATION OF A NON-COOPERATIVE OBJECT OF ON-ORBIT SERVICING
}

\author{
Institute of Technical Mechanics \\ of the National Academy of Sciences of Ukraine and the State Space Agency of Ukraine \\ 15 Leshko-Popel St., Dnipro 49005, Ukraine; e-mail: oafokov@ukr.net
}

\begin{abstract}
Many on-orbit servicing operations call for gripping a service object. One of the problems to be solved in gripping an object is to slow down its rotation. Examples of well-known projects for solving this problem are given. Based on the familiar concept of a two-stage gripping scheme and on the familiar concepts of the cellular architecture of a spacecraft and a space robot, it is proposed that the cellular architecture concept be applied to the construction of a self-contained system for slowing down the rotation of a non-cooperative object of on-orbit servicing. The system is made up of informationally connected modules or cells of minimum necessary functionality fixed on a service object (solid body). The minimum necessary functionality includes accelerometer-based measurement of the linear accelerations at the points of attachment of the sensor cells to the body, applying forces to the object using actuators in the form of propulsion systems, and data exchange and processing to determine the actuator forces. This paper addresses the problem of developing algorithms of the operation of the system considered, namely, determining the angular motion parameters and the center of mass position from the accelerometer data and determining control actions to slow down the rotation of the object. The aim of this work is to demonstrate the feasibility of the proposed self-contained system. The problems of estimation of the angular motion parameters and the center of mass position, braking impulse generation, and estimation of the object inertia tensor were reduced to finding the best linear unbiased estimate, the normal pseudosolution of an underdetermined system of algebraic equations, and the solution of an overdetermined one. A numerical simulation of the operation of the self-contained system was conducted, and the simulation results confirmed the operability of the proposed algorithms and thus the principle feasibility of the proposed self-contained system. The proposed concept of the construction of a self-contained system for slowing down the rotation of an object of on-orbit servicing and the system operation algorithm developed may be used in the design of on-orbit servicing spacecraft.
\end{abstract}

Keywords: on-orbit servicing, non-cooperative object, self-contained system for rotation slowing-down, operation algorithms, rotation characterization, control action generation.

1. Clerc X., Retat I. Astrium vision on space debris removal. Proceedings of 63rd International Astronautical 1. Congress. Naples, Italy, 2012. 13 pp.

2. Nishida S. Strategy for capturing of a tumbling space debris. Acta Astronautica. 2011. V. 68. Pp. 113-120. https://doi.org/10.1016/j.actaastro.2010.06.045

3. CleanSpace One Gripper Report. Phase 0. / Swiss Space Center EPFL; Lausanne, Switzerland, 2013. 57 pp.

4. Kitamura S., Hayakawa Y., Kawamoto S. A reorbiter for GEO large space debris using ion beam irradiation. Proceedings of 32nd International Electric Propulsion Conference. Wiesbaden, Germany, 2011. P. 13.

5. Bombardelli C., Pelaez J. Ion beam shepherd for contactless space debris removal. Journal of Guidance, Control and Dynamics. 2011. V. 34. No. 3. Pp. 916-920.

https://doi.org/10.2514/1.51832

6. Alpatov A. P., Fokov A. A., Khoroshylov S. V., Savchuk A. P. Error Analysis of method for calculation of non-contact impact on space debris from ion thruster. Mechanics, Materials Science \& Engineering. 2016. No. 5. Pp. 64-76.

7. Lavagna M., Benvenuto R., De Luca L., Maggi F., Tadini P., Graziano M. Contactless active debris removal: the hybrid propulsion alternative. Proceedings of 5th European Conference for Aerospace Sciences. Munich, 2013. P. 33. 
8. Golovko M. H., Bezugly V. A., Bondarenko S. G., Rubakha Y. A., Pokrovskiy R. O. Technical aspects of space refuse control. Ekology and Noospherology. 2012. V. 23. No. 1-2. Pp. 110-120. (in Russian).

9. Carroll J. A. Space Transport Development Using Orbital Debris: Final Report on NIAC Phase I / Tether Applications, Inc.; Research Grant No. 07600-087, 2002. 43 pp.

10. Gecko Gripper. NASA website. URL:

https://www.nasa.gov/mission_pages/station/research/experiments/explorer/Investigation.html?\#id=2057 (accessed on Oct. 10, 2019).

11. Jiang H., Hawkes E. W., Fuller C., Estrada M. A., Suresh S. A., Abcouwer N., Han A. K., Wang S., Ploch C. J., Parness A., Cutkosky M. R. A robotic device using gecko-inspired adhesives can grasp and manipulate large objects in microgravity. Science Robotics. 2017. V. 2. Iss. 7.45 pp. https://doi.org/10.1126/scirobotics.aan4545

12. Chang H., Huang P., Lu Z., Meng Z., Liu Z., Zhang Y. Cellular space robot and its interactive model identification for spacecraft takeover control. International Conference on Intelligent Robots and Systems (IROS). Daejeon, Korea. 2016. Pp. 3069-3074. https://doi.org/10.1109/IROS.2016.7759475

13. Chang H., Huang P., Lu Z., Meng Z., Liu Z., Zhang Y. Inertia parameters identification for cellular space robot through interaction. Aerospace Science and Technology. 2017. V. 71. Pp. 464-474. https://doi.org/10.1016/j.ast.2017.09.044

14. Brammer K., Siffling G. Kalman-Bucy Filter. Moscow, 1982. 200 pp. (in Russian).

15. Zhou B.-Z., Cai G.-P., Liu Y.-M., Liu P. Motion prediction of a non-cooperative space target. Advances in Space Research. 2017. V. 61. No. 1. Pp. 207-222. https://doi.org/10.1016/j.asr.2017.10.028

16. Korn G., Korn T. Mathematical Handbook. Moscow, 1974. 832 pp. (in Russian).

Received on November 5, 2019 , in final form on November 22, 2019 